\title{
Executive Functions: Influence of Sex, Age and Its Relationship With Intelligence ${ }^{1}$
}

\author{
Larissa de Oliveira e Ferreira ${ }^{2}$ \\ Pontifícia Universidade Católica de \\ Goiás, Goiânia-GO, Brazil
}

\author{
Daniela Sacramento Zanini \\ Pontifícia Universidade Católica de \\ Goiás, Goiânia-GO, Brazil
}

\author{
Alessandra Gotuzo Seabra \\ Universidade Presbiteriana Mackenzie, \\ São Paulo-SP, Brazil
}

\begin{abstract}
The Tower of Hanoi is a tool used to evaluate executive functions. However, few studies describe what functions are evaluated in this test. This study investigates the executive functions, evaluated by the Tower of Hanoi (ToH), and the influence of gender, age and its relationship with intelligence. We evaluated 55 children and adolescents, between the ages of ten and 16, without diagnosed neuropsychiatric disorders. The results showed that the performance and time in to complete the Tower of Hanoi have no discriminative power when comparing age groups and sex; there was also no significant correlation found between the ToH and the execution quotient of the Wechsler Intelligence Scale for Children - Third Edition (WISC III), perceptual organization and the speed of processing. Only the subtest coding were positively related to the ToH, demonstrating that these instruments may be measuring related aspects of intelligence and executive functions, namely intelligence and working memory.
\end{abstract}

Keywords: intelligence, children, adolescents

\section{Funções Executivas: Influência do Sexo, Idade e Sua Relação com Inteligência}

\begin{abstract}
Resumo: A Torre de Hanói é um instrumento utilizado para avaliação das funções executivas. Contudo, são escassos os estudos que descrevem quais são as funções avaliadas pelo teste. O objetivo deste estudo é investigar as funções executivas, avaliadas pela Torre de Hanói, verificando a influência de sexo, idade e sua relação com inteligência. Foram avaliadas 55 crianças e adolescentes entre 10 e 16 anos, sem diagnóstico de transtornos neuropsiquiátricos. Os resultados demonstraram que o desempenho e o tempo de realização do teste não têm poder discriminativo na comparação entre grupos etários e sexo, e tampouco se observou correlação significativa entre a ToH e o coeficiente de inteligência de execução do WISC III, a organização perceptiva e a velocidade de processamento. Apenas o subteste códigos relacionou-se positivamente com a ToH, demonstrando que esses instrumentos podem medir aspectos relacionados à inteligência e funções executivas, a saber, a inteligência e a memória de trabalho.
\end{abstract}

Palavras-chave: inteligência, crianças, adolescentes

\section{Funciones Ejecutivas: Influencia del Sexo, la Edad y Su Relación con la Inteligencia}

\begin{abstract}
Resumen: La Torre de Hanoi es una herramienta utilizada para evaluar las funciones ejecutivas. Sin embargo, hay pocos estudios que describen las funciones evaluadas en esta prueba. Este estudio investiga las funciones ejecutivas, evaluados por la Torre de Hanoi, la influencia del sexo, la edad y su relación con la inteligencia. Se evaluaron 55 niños y adolescentes entre diez y dieciséis años, sin diagnóstico de trastornos neuropsiquiátricos. Los resultados mostraron que el rendimiento y el tiempo en la Torre de Hanoi no tienen poder discriminativo cuando se comparan grupos de edad y sexo. Tampoco hubo correlación significativa entre ToH y el coeficiente de ejecución del WISC III, la organización perceptiva y la velocidad de procesamiento. Sólo el subtest códigos se relacionó positivamente con $\mathrm{ToH}$, demostrando que estos instrumentos pueden medir aspectos semejantes de la inteligencia y las funciones ejecutivas, a saber, la inteligencia y la memoria de trabajo.
\end{abstract}

Palabras clave: inteligencia, niños, adolescentes

Executive functions include responsible processes for focus, directing, regulating, managing and integrating cognitive functions related to everyday life tasks, as well as new and complex problems (Lezak, 1995; Miyake \& Friedman, 2012). These involve selection and integration of current information to those previously memorized, such as planning, monitoring and cognitive flexibility (Mourão Júnior \& Mello, 2011).

\footnotetext{
${ }^{1}$ Article derived from the master's thesis of the first author, under the supervision of the second author, defended in 2013, in the Graduate Program in Psychology at the Pontifícia Universidade Católica de Goiás.

${ }^{2}$ Correspondence address:

Larissa de Oliveira e Ferreira. Rua t-36, $n^{\circ} 3273$, apto.101, Setor Bueno. CEP

74223-055. Goiânia-GO, Brazil. E-mail: larissaoliveira10@hotmail.com
}

Because executive functions involve complex mental processes, several authors have suggested the need for identification of each of their components (Malloy-Diniz, Sedo, Fuentes, \& Leite, 2008; Miyake et al, 2000) and, among them: working memory, inhibitory control, planning, decision-making, cognitive flexibility, categorization and fluency. However, due to the lack of consensus on the components of executive functions, studies have been conducted in an attempt to identify them (Toplak, West, \& Stanovich, 2012).

One of the most currently accepted models is the empirical study by Miyake et al. (2000), which divided it into simple (with three components: inhibitory control, cognitive flexibility and working memory) and complex 
functions (involving two or three simple components). The authors evaluated 137 college students in 14 tests, with three tests for each single component of executive functions and five for complex components. Thus, three simple executive functions, with their respective instruments, Plus-minus, Number-Letter and Local-Global, were analyzed to assess cognitive flexibility; Keep Track, Tone Monitoring, Letter Memory for working memory, and the Anatisaccade, StopSignal, and Stroop for inhibitory control. Tasks of complex executive functions were also used, including the: Wisconsin Card Test, Tower of Hanoi, Random Number Generation, Operation Span and Dual Task.

The results indicated that: (a) three simple components of executive functions were moderately related, but clearly separable, suggesting unity and diversity of executive function; and (b) each of the three components differently contribute to complex task performance. Specifically, performance measured by the Wisconsin Card Test is more associated with cognitive flexibility, and the ToH with inhibition. The results of this research show the importance of recognizing both the unity and diversity of executive functions.

Significant differences are observed in executive functions according to sex. O'Brien, Dowell, Mostofsky, Denckla and Mahone (2010), for example, evaluated four components of executive functions (working memory, planning, inhibitory control and cognitive flexibility) of girls and boys with and without attention deficit hyperactivity disorder (ADHD), aged between eight and 14. In the study, three to four instruments were administered to measure each component of executive functions. The instruments used for working memory were: Conflicting Motor Response, PANESS Total Overflow, Go / No-Go, D-KEFS Color Word Interference for inhibitory control; WISC-IV Digit Span Backwards, Cantab Between Errors, D-KEFS Color Word Interference, WISC-III -PI Spacial Span Backwards; Cantab Spatial Working Memory Strategy Score, D-KEFS Tower, D-KEFS Trail Making for planning; D-KEFS Color - Word Interference, D-KEFS Trial Making, PANESS Total TIMED, Go / No-go Coefficient of Variability were used for cognitive flexibility. In the control group without ADHD, the results showed differences between sexes: girls were faster in performing the proposed tasks, but the boys had better accuracy in all evaluated components.

In another study, Sagrilo and Ferreira (2013) evaluated executive functions of children aged between six and seven years, comparing boys and girls, based on the working memory component, using verbal and visual span as instruments. The results showed that girls tended to have better performance in the verbal span, and boys in the visual span. In the study by Sant'Anna, Quayle, Pinto, Scaf and Lucia (2007), assessing executive functions of adolescents from 13 to 16 years, using the $\mathrm{ToH}$, the girls had better performance. Although these three studies show divergent data regarding sex, they were performed with different ages and instruments, which could explain the difference observed between sexes.

This study used the Tower of Hanoi (ToH), an assessment instrument for complex executive functions. According to Lezak (1995), the ToH evaluates planning, but also working memory, inhibitory control and cognitive flexibility, supporting the idea that this is a complex tool for executive function assessment. According to Diamond (2013), planning, the main construct evaluated by this test, can be considered part of the high level executive functions. Parallel to planning, this author also considers problem-solving and reasoning to be components of high level executive functions. Fluid intelligence can be understood as related to executive functioning, and therefore to planning.

In fact, both executive functions as well as intelligence are crucial for success in many everyday tasks (Brydges, Reid, Fox, \& Anderson, 2012). Therefore, recent studies have tried to differentiate them, or even understand the relationship between them. Intelligence is one of the most studied constructs within psychology, which probably hinders consensus on what it is and how to measure it (Primi, 2002). Theories suggest a multifactorial structure, considering that intelligence should be evaluated in various aspects and capabilities, as proposed by the Cattell-Horn-Carroll - (CHC) model. McGrew (2009) represents the cognitive abilities of two layers. The two layers consists of two general factors of intelligence, such as: fluid reasoning, quantitative reasoning, short-term memory, visual processing, auditory processing, storage and long-term associative recovery, cognitive processing speed, decision speed, reading and writing. The first layer has the specific factors: speed of reasoning, working memory, spatial analysis, fluency of words, ease to naming, spelling ability, among others. Schneider and McGrew (2012) had a broader intelligence classification that describes new general skills such as the domain of general independent abilities, acquired knowledge, specific sensory motor skills, and overall speed. In the new model, fluid intelligence is inserted in the group of general capabilities, and crystallized intelligence in the group of acquired knowledge or understanding/knowledge.

The relationship between fluid and crystallized intelligence with executive functions was widely researched by Friedman et al., (2006), as well as Brydges et al., (2012), who used the structure of the executive functions model of Miyake et al. (2000). There were 215 children tested, between seven and nine years. The results suggest that the development of fluid and crystallized intelligence and executive functions is enhanced according to the age, namely, older children performed better than younger children. In addition, the authors found that fluid and crystallized intelligence are highly associated with executive functions, particularly in childhood.

Godoy, Dias, Trevisan, Menezes, and Seabra (2010) found that research shows a correlation between intelligence and executive functions in general. However, the authors indicate a greater correlation between fluid intelligence and some components of executive functions, such as working memory and inhibitory control. These data confirm the McGrew and Flanagan (1998) postulations on the relationship between fluid intelligence and executive functions. For these authors, both involve mental operations that the individual performs when facing new situations.

In the Arffa (2007) investigation, which aimed to verify the relationship between intelligence and executive function, 
three groups of children and adolescents aged between six and 15 years were evaluated. The author administered the Wechsler Intelligence Scale for Children - Third Edition (WISC III) and five neuropsychological tests to assess executive functions (Wisconsin Card Sorting Test, Trail Making Test, Stroop Test, Word Fluency Test, and Design Fluency Test) and four neuropsychological tests of other nonexecutive skills (Rey Complex Figure Test, Rey Auditory Verbal Learning Test, Wide Range Achievement Test in Math). The results showed that the Stroop, Word Fluency, Design Fluency and Rey Complex Figure tests had significant correlations with intelligence, as measured by the WISC III.

The WISC III is still the most used instrument (Lopes, Farina, Wendt, Esteves, \& Argimon, 2012) to assess intelligence in children and adolescents. The WISC III is divided into two scales, verbal and performance, with 13 subtests. It is a reference tool for intelligence assessment of children and adolescents, extensively used by clinical psychologists and researchers. Today, however, this instrument is under review and a new revised edition (WISC IV) has just arrived within the Brazilian market. The new instrument has subtests for fluid intelligence evaluation, in order to provide a better measure of this component of intelligence.

During the WISC III test, time is a factor of extreme importance, because it is used as predictor of better or worse score, especially on the performance scale, which is a fundamental measure for assessing intelligence. Similar to what occurred in the assessment of intelligence, time was also used as a criterion for scoring measurement in executive functions evaluation, for example, in the Stroop or Trails tests (Lezak, 1995;. Malloy-Dinizet et al., 2008). The WISC III can be cited as an example because, despite it being an assessment test of intelligence, some of its action can be used to measure executive functions (Simões, 2002). The ToH, the object of this study, is another instrument used to evaluate executive functions which uses both time and correct answers for evaluation.

As the $\mathrm{ToH}$ is an instrument that is not yet standardized, most studies (Bishop, Aamodt-Leeper, Creswell, McGurk, \& Skuse, 2001; Wood, Oak, Rothe-Neves \& Haase, 2001) do not consider time during their administration, although it is checked and qualitatively accounted for within the analysis of results (Sant'Anna et al., 2007). The aim of this study is to investigate executive functions, assessed by the ToH, checking the influence of gender, age and its relationship with intelligence. The number of movements and runtime measurements were used, that is, how many movements and how much time is needed for the children or adolescents to solve the proposed task, considering the influence of gender and age and its relationship with intelligence.

\section{Method}

\section{Participants}

Participants were selected according to convenience criteria, and recruited in nine public and 11 private schools of elementary degree and high school. Parents or guardians were required to agree and sign the Terms of Free and Informed
Consent for their children to participate in the study. The inclusion criteria was: aged 10-16 years and 11 months, attending elementary or high school, enrolled in a school. Exclusion criteria were: developmental delay complaints, cognitive dysfunction, neuropsychiatric disorders, and historical or current consumption of psychotropic medication, alcohol or drugs, as reported by the parents. According to these criteria, 55 children and adolescents were included in the survey; 26 boys and 29 girls, aged between $10-16$ years and 11 months $(M=13.33, S D=1.84)$, as shown in Table 1 .

Table 1

Distribution (Frequency and Percentage) of Participants According to Sex and Age

\begin{tabular}{lrrrrrr}
\hline Age & \multicolumn{2}{c}{ Boys } & \multicolumn{2}{c}{ Girls } & \multicolumn{2}{c}{ Total } \\
\hline & $f$ & $\%$ & $f$ & $\%$ & $f$ & $\%$ \\
\cline { 2 - 7 } 10 & 1 & 3.8 & 1 & 3.4 & 2 & 3.6 \\
11 & 6 & 23.1 & 2 & 6.9 & 8 & 14.5 \\
12 & 8 & 30.8 & 4 & 13.8 & 12 & 21.8 \\
13 & 4 & 15.4 & 4 & 13.8 & 8 & 14.5 \\
14 & 4 & 15.4 & 4 & 13.8 & 8 & 14.5 \\
15 & 1 & 3.8 & 6 & 20.7 & 7 & 12.8 \\
16 & 2 & 7.7 & 8 & 27.6 & 10 & 18.3 \\
Total & 26 & 100.0 & 29 & 100.0 & 55 & 100.0 \\
\hline
\end{tabular}

\section{Instruments}

Questionnaire of socio demographic data. Containing questions related to type of school (public or private), family income, number of people living in the house, dominant hand of participants, and use of medications.

Tower of Hanoi Test. Instrument of wood with rectangular base and three pins of $12 \mathrm{~cm}, 4$ square pieces of different sizes and colors, which should be placed from the biggest size to the smallest and from the bottom to the top. The instructions are:
"We will perform a task called the Tower of Hanoi. In this task you will transpose the parts that are on this pin (pointing to) to the latter pin in here (pointing to). For this, you must follow these rules: you can move only one disk at a time and you can use all the pins, since the smaller disk always must be on top. It is not allowed for there to be a large disc on top of a small disk. You need to solve this challenge with the smallest number of moves you can make. Any questions? Let's start!"

Two items were presented in this task, one item with three pieces, and the other with four pieces. The child should begin with the left three pieces transposing them to the right pin; she could use the center pin. The timer was triggered when the movement of pieces began. Each correct movement was counted as one point (Sant'Anna et al., 2007). The timer was 
reset and the first attempt was finished at the completion of the correct movement of the pieces, when changing them from the right pin to the left. Similarly, the timer was reset with the second and third attempt for all administrations (cases). The movement of a piece without a pin removal was not counted as a movement. The movement was defined as the removal of a piece and its transposition onto another pin. Errors, such as putting a larger piece above a smaller one, keeping two pieces in one's hand, or leaving a piece on the table were not considered. The child was instructed to return the piece to the previous position, when the error occurred, and the clock continued to measure time. Thus, the score corresponded to the sum of all the correct movements in all three trials (including the times that the attempt had to be restarted due to error) and the time equivalent to the mean of the total time used in the three attempts. After three attempts with three parts, the child performed the task again with four pieces, in accordance to the prior rules. Likewise, scores were calculated for the total (sum of all the correct movements even when it was necessary to restart) and time (mean time in three attempts).

WISC III Performance Scale. This is a widely used test to assess intelligence both in the clinical area and in research (Wechsler, 2002). Its use is restricted to psychology professionals and was approved by the Federal Council of Psychology (CFP Resolution No. 002/2003.) in November, 2003. Recognized in several studies, it has good psychometric qualities (Lopes et al., 2012; Simões, 2002 ). Although international studies are already being conducted with the WISC IV, since 2003 (Watkins \& Smith, 2013), until the time of this data collection, only the WISC III was available for use in Brazil.

The WISC III consists of 13 subtests divided into verbal and performance scales. The performance scale consists of seven subtests (picture completion, coding, picture arrangement, blocks, object assembly, symbol search, and mazes). The verbal intelligence quotient (VQ), performance quotient (PQ), and the overall quotient (OQ) are obtained with subtests scores. In addition to the measurement of intelligence quotients (IQ), the performance scale provides indexes associated with specific skills such as verbal understanding (information, similarities, vocabulary, and comprehension), perceptual organization (picture completion, picture arrangement, object assembly, and blocks) resistance to distraction (arithmetic and digits) and processing speed (coding and symbol search).

The performance scale subtests used were, respectively: (a) picture completion - attention to the environment, concentration and relationship of whole to part perception; (b) coding - measures the ability to associate numbers and symbols, with the correct memorization of associations, evaluates the processing speed, ability to follow directions under pressure related to time, mental flexibility, capacity for learning, and mental efficiency; (c) picture arrangement evaluates the ability to integrate and organize in a logical way; (d) block - examines organizational skills and visual-spatial processing. (e) object assembly - measures the capacity for synthesis, which provides for strategy observation and problem solving; (f) symbol search - evaluates perceptual discrimination ability, working memory, short term memory concentration; (g) mazes - examines the ability for anticipation and planning, which requires visual-spatial strategy in working memory (Wechsler, 2002).

\section{Procedure}

Data collection. Data collection was performed in the school attended by the students, in a large, airy room separate from the classroom. Participants individually had the ToH test administered in two steps, with three and four pieces, setting up three attempts at each step to get to the solution. The time spent was timed for all attempts, beginning with the first movement and reset only at the end of each attempt. Later, participants had seven subtests of the WISC III Performance Scale administered, in an individual way, according the guidelines for WISC III subtest application, contained in the manual. The performance IQ (PQ) calculation was based on the five subtests that comprise it, as stated in the manual.

Data analysis. All dependent variables in this study exhibited a normal distribution, according to the KolmogorovSmirnov test, which allowed the use of parametric statistics. The student's t-test was performed to compare means in order to assess whether there was a significant difference between the number of movements performed in each attempt, and time spent to perform the $\mathrm{ToH}$ (with three or four pieces), between boys and girls and between the two age groups. The Cohen's $d$ technique (Maroco, 2010) was used to calculate the effect-size. A Pearson correlation analysis was conducted to verify the relationship between the number of movements for each attempt and the time spent to perform the ToH (with three or four pieces), as well as the number of movements and time to perform the ToH and the WISC III subtest execution, IQ execution, perceptual organization, and processing speeds. All analyses were performed using the Statistical Package for the Social Sciences software for Windows (SPSS) version 20.0 , with a confidence interval of $95 \%$.

\section{Ethical Considerations}

After approved by the Ethics Committee of the Pontifícia Universidade Católica de Goiás (Protocol 0056.0.168.000-11), contact with institutions and a school (private and public) was established. The Terms of Free and Informed Consent were signed by parents or guardians, after necessary clarifications about participation. Data collection was scheduled only after the signed Terms were returned to the researcher.

\section{Results}

Comparison of mean analyses and correlations between sociodemographic variables and the performance on the WISC III Performance Scale and ToH were conducted. Differences or significant relationships for any evaluated sociodemographic variables (type of school, family income, and number of people living in the house, dominant hand of 
participants and use of medications) were not found. As a consequence, the remaining analyses were conducted without the controlled influence of these variables.

Possible differences between groups, in relation to sex and age, were verified by Student's t-tests. In comparing ages, the sample was clustered into two groups, according to age. The clustering followed the proportionality of participants, as well as the development of theories. So, participants aged between 10-13 years were classified as group 1, and participants aged between 14-16 years, as group 2. Table 2 shows the comparison between sex and the two age groups for each of the three attempts with three or four pieces, as well as the mean number of movements per attempt, and the time, in minutes, for the ToH, as well as the effect-size analysis by Cohen- $d$.

Table 2

Comparison Between Sex and Different Age Groups for Attempts and Time (Minutes) for the ToH With Three and Four Pieces (Mean)

\begin{tabular}{|c|c|c|c|c|c|c|c|c|c|}
\hline & & \multicolumn{8}{|c|}{ Groups } \\
\hline & & \multicolumn{4}{|c|}{ Sex } & \multicolumn{4}{|c|}{ Age } \\
\hline & & Boys & Girls & Student $\mathrm{t}$ & Cohen d & $\begin{array}{l}\text { Group } 1 \\
(10-13 a)\end{array}$ & $\begin{array}{l}\text { Group } 2 \\
(14-16 a)\end{array}$ & Student $t$ & Cohen d \\
\hline & & $\begin{array}{c}M \\
(S D)\end{array}$ & $\begin{array}{c}M \\
(S D)\end{array}$ & $\begin{array}{l}t \\
p\end{array}$ & $\begin{array}{l}d \\
r\end{array}$ & $\begin{array}{c}M \\
(S D)\end{array}$ & $\begin{array}{c}M \\
(S D)\end{array}$ & $\begin{array}{l}t \\
p\end{array}$ & $\begin{array}{l}d \\
r\end{array}$ \\
\hline \multirow{2}{*}{3 pieces } & M & $\begin{array}{c}32.06 \\
(11.09)\end{array}$ & $\begin{array}{l}27.64 \\
(8.78)\end{array}$ & $\begin{array}{r}1.60 \\
.12\end{array}$ & $\begin{array}{r}0.44 \\
.22\end{array}$ & $\begin{array}{c}31.54 \\
(19.77)\end{array}$ & $\begin{array}{l}27.66 \\
(8.86)\end{array}$ & $\begin{array}{r}1.46 \\
.15\end{array}$ & $\begin{array}{r}0.25 \\
.13\end{array}$ \\
\hline & $\mathrm{T}$ & $\begin{array}{c}2.78 \\
(5.84)\end{array}$ & $\begin{array}{c}1.34 \\
(0.97)\end{array}$ & $\begin{array}{r}1.25 \\
.19\end{array}$ & $\begin{array}{r}0.34 \\
.17\end{array}$ & $\begin{array}{c}2.68 \\
(5.47)\end{array}$ & $\begin{array}{c}1.23 \\
(0.72)\end{array}$ & $\begin{array}{r}1.43 \\
.16\end{array}$ & $\begin{array}{r}0.37 \\
.18\end{array}$ \\
\hline \multirow{2}{*}{4 pieces } & M & $\begin{array}{c}72.30 \\
(17.78)\end{array}$ & $\begin{array}{c}64.90 \\
(29.62)\end{array}$ & $\begin{array}{r}1.14 \\
.26\end{array}$ & $\begin{array}{r}0.30 \\
.15\end{array}$ & $\begin{array}{c}73.43 \\
(28.95)\end{array}$ & $\begin{array}{c}62.37 \\
(17.38)\end{array}$ & $\begin{array}{r}1.74 \\
.86\end{array}$ & $\begin{array}{r}0.46 \\
.23\end{array}$ \\
\hline & $\mathrm{T}$ & $3.63(2.10)$ & $\begin{array}{c}5.55 \\
(11.05)\end{array}$ & $\begin{array}{r}-0.92 \\
.37\end{array}$ & $\begin{array}{r}-0.24 \\
-.12\end{array}$ & $\begin{array}{c}5.45 \\
(9.59)\end{array}$ & $\begin{array}{c}3.68 \\
(3.43)\end{array}$ & $\begin{array}{r}0.87 \\
.39\end{array}$ & $\begin{array}{r}0.25 \\
.12\end{array}$ \\
\hline
\end{tabular}

Note. $\mathrm{M}=$ movement; $\mathrm{T}=$ time.

No significant difference between sex and age groups was observed for any measure, either in terms of mean number of movements or in relationship to mean time, in minutes, for completion of the ToH test, either with three or four pieces. The effect-size analysis presented $d$ values between -.24 and .46 , indicating a small to moderate effect, which means that the results were lightly or moderately influenced by the sample size.

A Pearson's correlation analysis was conducted to assess whether there was a correlation between the time and the performance of the ToH, in terms of number of movements. The data indicated no significant relationship for this sample, showing that the time spent to achieve the evidence did not influence the number of movements performed (Table 3).

The Pearson's correlation was used to analyze the relationship between performance in the ToH test, in terms of mean number of movements and time spent for three and four pieces, and the performance on the WISC III Performance Scale, including PQ, perceptual organization scales and processing speed, as well as gross and weighted scores for each subtest. Significant correlations with performance on the IQ (PQ) or scales were not observed. Regarding the subtests, only Coding showed a significant correlation. For this reason, only this subtest is presented in Table 3, in addition to PQ data, perceptual organization and processing speed.

Table 3

Pearson Correlation Coefficients (r) Between Number of Movements and Time for the ToH With Three and Four Pieces and IQ Performance, Perceptual Organization, Speed Processing and WISC III Coding

\begin{tabular}{|c|c|c|c|c|c|c|c|c|c|c|}
\hline \multicolumn{11}{|c|}{ WISC III Perfromance Scale } \\
\hline & & \multicolumn{2}{|c|}{3 pieces } & \multicolumn{2}{|c|}{4 pieces } & \multirow{2}{*}{$\begin{array}{c}\text { QI } \\
\text { Performance }\end{array}$} & \multirow{2}{*}{$\begin{array}{c}\text { Perceptual } \\
\text { organization }\end{array}$} & \multirow{2}{*}{ Speed processing } & \multirow{2}{*}{$\begin{array}{c}\text { Coding* } \\
\text { (Gross score) }\end{array}$} & \multirow{2}{*}{$\begin{array}{c}\text { Coding* } \\
\text { (weigted score) }\end{array}$} \\
\hline & & M & $\mathrm{T}$ & $\mathrm{M}$ & $\mathrm{T}$ & & & & & \\
\hline \multirow{2}{*}{3 pieces } & $\mathrm{M}$ & -- & .01 & .24 & -.08 & -.14 & -.18 & .05 & -.39 & .03 \\
\hline & $\mathrm{T}$ & .01 & -- & .17 & .19 & .09 & .08 & -.06 & -.21 & -.21 \\
\hline \multirow{2}{*}{4 pieces } & M & .24 & .17 & -- & .20 & -.11 & -.04 & -.18 & $-.28 *$ & $-.27 *$ \\
\hline & $\mathrm{T}$ & -.07 & .19 & .20 & -- & .09 & .21 & .18 & -.05 & -.09 \\
\hline
\end{tabular}

Note. $\mathrm{M}=$ movement; $\mathrm{T}=$ time.

*Although all subtests that comprise the WISC III Performance Scale were applied, only the Coding subtest showed a significant relationship with the ToH. So, for reasons of space, only the results for this subtest are displayed. 


\section{Discussion}

This study aimed to investigate the executive functions, evaluated by the $\mathrm{ToH}$, by verifying the influence of sex, age and its relationship with intelligence. According to the study by O'Brien et al. (2010), results suggest a difference between the boys' and girls' performance in the number of movements and the $\mathrm{ToH}$ runtime, with the boys showing more movement and less runtime than girl. However, no significant differences were observed between boys and girls in this study, and the effect size analysis showed that the sample size had a light or moderate influence on the results (Maroco, 2010).

Lynn and Kanazawa (2011) indicate a variation in the overall development of boys and girls in early adolescence, but with a tendency toward equivalence, through the years, which could explain the data found in this study for Group 2, aged 14 - 16, but not for Group 1, aged $10-13$ years. However, St. Anna et al. (2007) in their research with adolescents of 1316 years, found significant differences between sexes. This general principle of sex differences related to maturation rate can be applied to the development of cognitive skills, according to Flores-Mendoza, Mansur-Alves, Lelé, and Flag (2007) and, consequently, of executive functions. However, considering that this study had a small sample $(N=55)$ and a wide dispersion of age (10-16 years), with a concentration in the 13 year olds $(M=13.33)$, these results should be taken with caution and they cannot be generalized.

Studies using the $\mathrm{ToH}$ to evaluate executive functions of children and adolescents with normal development in the age group studied are scarce in Brazil, complicating associations related to the results. There are foreign studies, conducting comparisons with groups of children with disorders (O'Brien et al., 2010), seeking standardization of the ToH test (Sant'Anna et al., 2007), or a relationship with fluid intelligence (Brydges et al., 2012).

No significant differences were found in execution time and number of movements in the different age groups (10-13 and 14-16 years), different from previously reported studies in the literature. The results of research by Friedman et al. (2006), suggested that the development of executive functions, fluid intelligence and crystallized intelligence is enhanced according to age; so, age interferes with the performance of executive and cognitive functions. Also, Shing, Lindenberg, Diamond, Li, and Davidson (2010) showed that working memory and inhibition increase with age in children aged 4-14, and Bishop et al. (2001), comparing the $\mathrm{ToH}$ performance between groups of children and adolescents, aged between 7-15 years and adults, found significant differences between groups. However, the application form was not the same as in this research.

The presented data of this study, in general, showed improvement in performance according to the age when the mean was observed. However, there was no significant difference in comparing age groups. However, these findings should be further explored in future studies with a larger group of participants, as well as different age groups.

Some research showed high correlations between the
ToH testing and fluid intelligence (Batista, Adda, Miotto, Lucy, \& Scaff, 2007; Colom, Rubio, Shih, \& Santacreu, 2006; Zook, Davalos, Delosh, \& Davis, 2004). The results for Zook et al., (2004) indicate that performance on $\mathrm{ToH}$ is influenced by fluid intelligence, working memory and inhibitory control, namely, by two components of executive function and fluid intelligence.

Colom et al., (2006), in a study with 229 participants, with a mean age of 28 years, related fluid intelligence and executive functions and more specifically, working memory. The authors demonstrated that the relationship between executive functions (measured by $\mathrm{ToH}$ ) and fluid intelligence (measured by a computerized test called Trasi, similar to Raven) is greater than the ratio between fluid intelligence and working memory, specifically.

Arffa (2007) conducted a study aiming to investigate the relationship between intelligence and executive function in children and adolescents aged between 6-15 years, using the WISC III as a measure of intelligence, and five neuropsychological tests to assess executive functions (Categorization Wisconsin Cards Sorting, Trail Making, Stroop, Word Fluency and Design Fluency tests). The author pointed out that results in the Stroop, Word Fluency and Rey Complex Figure tests had significant correlation with intelligence measured by the WISC III.

An international theoretical study was conducted by Batista et al., (2007), comparing cognitive and methodological aspects involving the $\mathrm{ToH}$ and the Tower of London. In preschool groups, fluid intelligence, working memory and inhibitory control, when observing the two towers, only the $\mathrm{ToH}$ showed these three components as predictors. Batista et al., (2007), Colom et al., (2006), and Zook et al., (2004) found significant correlations between performance in the $\mathrm{ToH}$ and fluid intelligence. This study did not find relationships between intelligence and performance of the ToH; this may be because the test was used for evaluation. Perhaps, using a more specific test for fluid intelligence could show higher correlation with performance in the ToH, which may represent a limitation of this study.

However, although it is understandable that there is no relationship between intelligence, as measured by the WISC III performance scale, and executive function, as measured by the $\mathrm{ToH}$, a greater correlation with factor levels or performance in specific subtests should be expected, which did not occur in this study, as only the Coding subtest showed significant relationship with the ToH. However, there are no studies that could negate or support this result.

The Coding subtest measures the ability to memorize associations, and evaluates the mechanical learning capacity (Simões, 2002), the working memory and inhibitory control. The working memory and inhibitory control are components of executive functions which, according to most studies are measured by the $\mathrm{ToH}$, which may explain the significant relationship between the two tests. In the Coding subtest, for example, the child should memorize the data from the tasks, writing them, and in the $\mathrm{ToH}$, she must memorize the correct movement for achieving the goal. This type of working memory, more linked to the implementation of concrete tasks and little 
to abstract reasoning, can be a type of more specific memory. Therefore, comparison studies are suggested, especially in age groups similar to this research who have normal development, in order to corroborate the findings.

Finally, analysis of the influence of time on performance, in terms of the number of movements in the ToH, did not show a significant relationship, indicating that, for this sample, the time spent in testing does not interfere with the test performance, concerning the number of movements performed and therefore, showing a greater accuracy in testing. This fact brings into discussion the importance of time in evaluating intelligence performance and executive functions. Further studies with different methodological designs and with probability samples could further elucidate these findings.

In summary, this research revealed that the number of movements and the measurement of time to complete the $\mathrm{ToH}$, performance scale with children from 10-16 years, had no discriminative power, when comparing the groups of t1013 , and 14-16 years and between the sexes. Consequently, the runtime of $\mathrm{ToH}$ performance is not a discriminating factor, according to the data collected, in the case of children from 10-16 years, according to data from this study. However, this data should be taken with caution and cannot be generalized.

The small number of participants (55 subjects), and the age dispersion, prevented a more detailed analysis of human development, and were factors that hindered detailed and accurate data. Absence of consensus on the processes involved in the ToH performance (Batista et al., 2007) is another issue. Some studies use the $\mathrm{ToH}$ as a measure of executive function in general (Colom et al., 2006), others, as a measure of working memory (Batista et al., 2007), inhibitory control (Batista et al., 2007; Brydges et al., 2012), cognitive flexibility and planning (Bishop et al., 2001; O'Brien et al., 2010; Sant'Anna et al., 2007).

Contrary to what was expected, data showed that the ToH is not related to the PQ in accordance with WISC III, either when comparing the number of movements or the time required for completion. However, the literature suggests that the ToH can be a good measure of working memory and intelligence, particularly because it was significantly correlated with the Coding subtest that evaluates these components. However, more research needs to be conducted to confirm this hypothesis. Therefore, further studies on the importance of the $\mathrm{ToH}$ in the evaluation of executive functions, the influence of age and sex on the executive functions, and the relationship of intelligence to executive functions involving larger samples and children with normal development must be conducted.

\section{References}

Arffa, S. (2007).The relationship of intelligence to executive function and non-executive function measures in sample of average, above average and gifted youth. Archives of Clinical Neuropsychology, 22(8), 969-978. doi:10.1016/j. acn.2007.08.001
Batista, A. X., Adda, C. C., Miotto, E. C., Lúcia, M. C. S., \& Scaff, M. (2007). Torre de Londres e Torre de Hanói: Contribuições distintas para avaliação do funcionamento executivo [Tower of London and Tower of Hanoi: Distinct contributions to the assessment of executive functioning]. Jornal Brasileiro de Psiquiatria, 56(2), 134-139. doi:10.1590/S0047-20852007000200010

Bishop, D. V. M., Aamodt-Leeper, G., Creswell, C., McGurk, R., \& Skuse, D. H. (2001). Individual differences in cognitive planning on the Tower of Hanoi task: Neuropsychological maturity or measurement error? Journal Child Psychology Psychiatry, and Allied Disciplines, 42(4), 551-556. doi:10.1017/ S0021963001007247

Brydges, C. R., Reid, C.L., Fox, A.M., \& Anderson, M. (2012). A unitary executive function predicts intelligence in children. Intelligence, 40(5), 458-469. doi:10.1016/j. intell.2012.05.006

Colom, R., Rubio, V. J., Shih, P. C., \& Santacreu, J. (2006). Fluid intelligence, working memory and executive functioning. Psicothema, 18(4), 816-821.

Conselho Federal de Psicologia. (2003, março). Resolução CFP $N^{o}$ 002. Define e regulamenta o uso, a elaboração e a comercialização de testes psicológicos e revoga a Resolução CFP no 025/2001 [Defines and regulates the use, development and marketing of psychological tests and repealing CFP Resolution No. 025/2001]. Retrieved from http://www.serdigital.com.br/gerenciador/clientes/ crp/arquivos/70.pdf

Diamond, A. (2013). Executive functions. Annual Review of Psychology, 64, 135-168. doi:10.1146/annurevpsych-113011-143750

Flores-Mendonza, C. E., Mansur-Alves, M., Lelé, A. J., \& Bandeira, D. R. (2007). Inexistência de diferenças de sexo no fato $g$ (Inteligência geral) e nas habilidades específicas em crianças de duas capitais brasileiras [There are no sex differences on $\mathrm{g}$ factor and specific abilities in children from two Brazilian capitals]. Psicologia: Reflexão e Crítica, 20(3), 499-506. doi:10.1590/S010279722007000300018

Friedman, N. P., Miyake,A., Corley, R.P.,Young, S.E., DeFries, J. C., \& Hewitt, J. K. (2006). Not all executive functions are related to intelligence. Psychological Science, 17(2), 172-179. doi:10.1111/j.1467-9280.2006.01681.x

Godoy, S., Dias, N. M., Trevisan, B. T., Menezes A., \& Seabra, A. G. (2010). Concepções teóricas acerca das funções executivas e das altas habilidades [Theoretical conceptions on the executive functions and high abilities]. Cadernos de Pós-Graduação em Distúrbios do Desenvolvimento, 10(1), 76-85.

Lezak, M. D. (1995). Executive functions and motor performance. In Neuropsychological assessment (3rd ed., pp. 650-685). New York, NY: Oxford University Press.

Lopes, R. M., Farina, M., Wendt, G. W., Esteves, C. S., \& Argimon, I. I. L. (2012). Sensibilidade do WISC III na identificação do transtorno de déficit de atenção/ hiperatividade (TDAH) [WISC-III Sensibility in the 
identification of attention deficit hyperactivity disorder (ADHD)]. Cuadernos de Neuropsicología, 6(1), 128140. doi:10.7714/cnps/6.1.208

Lynn, R., \& Kanazawa, S. (2011). A longitudinal study of sex differences in intelligence at ages 7,11 and 16 years. Personality and Individual Differences, 51(3), 321-324. doi:10.1016/j.paid.2011.02.028

Malloy-Diniz, L. F., Sedo, M., Fuentes, D., \& Leite, W. B. (2008). Neuropsicologia das funções executivas [Neuropsychology of executive functions]. In D. Fuentes, L. F. Malloy-Diniz, C. H. P. Camargo, \& R. M. Consenza (Eds.), Neuropsicologia: Teoria e prática [Neuropsychology: Theory and practice] (pp. 187-206). Porto Alegre, RS: Artmed.

Marôco, J. (2010). Análise estatística com utilização do SPSS [Estatistic analysis using SPSS] (3rd ed.). Lisboa, Portugal: Sílabo.

McGrew, K. S. (2009). CHC theory and the human cognitive abilities project: Standing on the shoulders of the giants of psychometric intelligence research. Intelligence, 37(1), 1-10. doi:10.1016/j.intell.2008.08.004

McGrew, K. S., \& Flanagan, D. P. (1998). The Intelligence Test Desk Reference (ITDR): Gf-Gc cross-battery assessment. Needham Heights, MA: Allyn \& Bacon.

Miyake, A., \& Friedman, N.P. (2012). The nature and organization of individual differences in executive functions: Four general conclusions. Current Directions in Psychological Science, 21(1), 8-14. doi:10.1177/0963721411429458

Miyake, A., Friedman, N. P., Emerson, M. J., Witzki, A. H., Howerter, A., \& Wager, T. D. (2000). The unity and diversity of executive functions and their contributions to complex "frontal lobe" tasks: A latent variable analysis. Cognitive Psychology, 4l(1), 49-100. doi:10.1006/ cogp.1999.0734

Mourão Júnior, C. A., \& Melo, L. B. R. (2011). Integração de três conceitos: Função executiva, memória de trabalho e aprendizado [Integration of three concepts: Executive function, working memory and learning]. Psicologia: Teoria e Pesquisa, 27(3), 309-314. doi:10.1590/S010237722011000300006

O'Brien, J. W., Dowell, L. R., Mostofsky, S. H., Denckla, M. B., \& Mahone, E. M. (2010). Neuropsychological profile of executive function in girls with attentiondeficit/hyperactivity disorder. Archives of Clinical Neuropsychology, 25(7), 656-670. doi:10.1093/arclin/ acq050

Primi, R. (2002). Inteligência fluida: Definição fatorial, cognitiva e neuropsicológica [Fluid intelligence: Factorial definition, cognitive and neuropsychological]. Paidéia (Ribeirão Preto), 12(23), 57-75. doi:10.1590/S0103$863 X 2002000200005$

Sagrilo, M. C. P., \& Ferreira, T. L. (2013). Diferença entre span verbal e visual nos gêneros: Estudo piloto [Difference between verbal and visual span in genders: Pilot study]. CEFAC, 15(3), 552-560.

Sant'Anna, B. A., Quayle, J., Pinto, K. O., Scaf, M., \& Lúcia,
M. C. S. (2007). Torre de Hanói: Proposta de utilização do instrumento para sujeitos de 13 a 16 anos [Tower of Hanoi: Proposal to use the instrument for subjects 13 to 16 years]. Psicologia Hospitalar, 5(2), 36-56.

Schneider, W. J., \& McGrew, K. S. (2012). The Cattell-HornCarroll model of intelligence. In D. P. Flanagan \& P. L. Harrison (Eds.), Contemporary intellectual assessment: Theories, tests, and issues (3rd ed., pp. 99-144). New York, NY: Guilford.

Shing, Y. L., Lindenberg, U., Diamond, A.,Li, S.-C., \& Davidson, M. C. (2010). Memory maintenance and inhibitory control differentiate from early childhood to adolescence. Developmental Neuropsychology, 35(6), 679-697. doi:10.1080/87565641.2010.508546

Simões, M. R. (2002). Utilizações da WISC-III na avaliação neuropsicológica de crianças e adolescentes [Uses of the WISC-III in the neuropsychological assessment of children and adolescents]. Paidéia (Ribeirão Preto), 12(23), 113132. doi:10.1590/S0103-863X2002000200009

Toplak, M. E., West, R. F., \& Stanovich, K. E. (2012). Practitioner review: Do performance-based measures and ratings of executive function assess the same construct? Journal of Child Psychology and Psychiatry, and Allied Disciplines, 54(2), 131-143. doi:10.1111/jcpp.12001

Watkins, M. W., \& Smith, L. G. (2013). Long-term stability of the Wechsler Intelligence Scale for Children-Fourth Edition. Psychological Assessment, 25(2), 477-483. doi:10.1037/a0031653

Wechsler, D. (2002). WISC III: Escala de Inteligência Wechsler para crianças: Manual [WISC III: Wechsler Intelligence Scale for children: Manual]. (3rd ed., V. L. M. Figueiredo, Trans.). São Paulo, SP: Casa do Psicólogo.

Wood, G. M. O., Carvalho, M. R. S., Rothe-Neves, R., \& Haase, V. G. (2001).Validação da Bateria de Avaliação da Memória de Trabalho (BAMT-UFMG) [Validation of Working Memory Assessment Battery (BAMTUFMG)]. Psicologia: Reflexão e Crítica, 14(2), 325-341. doi:10.1590/S0102-79722001000200008

Zook, N. A., Davalos, D. B., DeLosh, E. L., \& Davis, H. P. (2004). Working memory, inhibition, and fluid intelligence as predictors of performance on Tower of Hanoi and London tasks. Brain and Cognition, 56(3), 286-292. doi:10.1016/j.bandc.2004.07.003 
Ferreira, L. O., Zanini, D. S., \& Seabra, A. G. (2015). Executive Functions, Sex, Age and Intelligence.

Larissa de Oliveira e Ferreira is a Professor at Pontifícia Universidade Católica de Goiás.

Daniela Sacramento Zanini is a Professor at Pontifícia Universidade Católica de Goiás.

Alessandra Gotuzo Seabra is a Professor at Universidade Presbiteriana Mackenzie.

Received: Sep. 30, 2014

1st Revision: Feb. 6, 2015

Approved: Mar. 25, 2015

How to cite this article:

Ferreira, L. O., Zanini, D. S., \& Seabra,A. G. (2015). Executive functions: Influence of sex, age and its relationship with intelligence. Paidéia (Ribeirão Preto), 25(62), 383-391. doi:10.1590/1982-43272562201512 